RAS ONCOLOGY \& THERAPY

\title{
Short Communication : Retrospective analysis of postmenopausal patients with hyperthyroidism and possible association with lung cancer in a Primary Health Care Setting in Western Greece
}

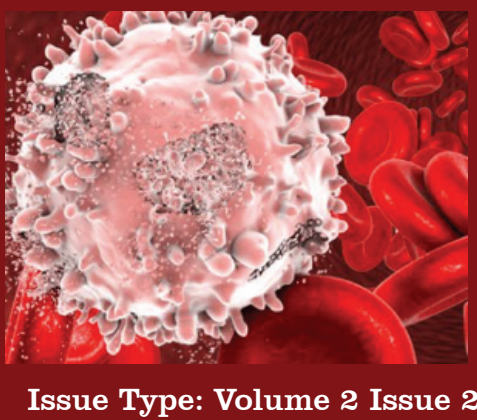

Author Name:

Athanasia Moutafidi, Biologist, M.Sc. Microbiology Department, General Hospital of Eastern Achaia, Kalavrita, Greece

Charalampos Potsios, M.D.

Senior, Internal Medicine Department, University General Hospital of Patras, Greece

Panagiota Xaplanteri, M.D., PhD, M.Sc. Head of Microbiology Department, General Hospital of Eastern Achaia, Kalavrita, Achaia, Greece

Corresponding Author:

Panagiota Xaplanteri, M.D., Ph.D. M.Sc.

Citation: Panagiota Xaplanteri, M.D., Ph.D. M.Sc.

Retrospective analysis of postmenopausal patients with hyperthyroidism and possible association with lung cancer in a Primary Health Care Setting in Western Greece

Received Date: 5th Oct 2021

Published Date: 21th Oct 2021

Copyrights: Panagiota Xaplanteri, M.D., Ph.D. M.Sc.,

This is an open access article distributed under the Creative Commons Attribution License, which permits unrestricted use, distribution, and reproduction in any medium, provided the original work is properly cited.

\begin{abstract}
:
The role of thyroid hormones when circulating at high levels has been shown to have an estrogen-like effect. Estrogens play an important role in lung carcinogenesis. The aim of this study was the retrospective analysis of the laboratory results of postmenopausal women with hyperthyroidism and simultaneous measurement of the tumor marker carcinoembryonic antigen (CEA) and the possible correlation of the findings with lung cancer. The data of the patients who met the above criteria were collected retrospectively from the Microbiological Department of a Primary Health Care Setting in Western Greece for the years 2018, 2019, 2020. Nine patients met the study criteria, and of them one was diagnosed with lung cancer. This study does not indicate direct cause-effect correlation. However, increased vigilance for lung neoplasm in postmenopausal female patients with hyperthyroidism may be an additional auxiliary tool in the assessment and early diagnosis of these patients especially in a Primary Health Care Setting.
\end{abstract}

Key words: Lung cancer, thyroid hormones, hyperthyroidism, postmenopausal women

\section{Introduction :}

Lung cancer is the second most common cancer in women after breast cancer and the second leading cause of cancer-related death in women worldwide. It has been suggested by many researchers that estrogens play an important role in lung carcinogenesis. ${ }^{1}$ The role of thyroid hormones when circulating at high levels has also been shown to have an estrogen-like effect. ${ }^{1}$

The aim of the present study was the retrospective analysis of the laboratory profile of postmenopausal women who attended the Microbiology Laboratory of a Primary Health Care Setting with hyperthyroidism and the possible correlation of the findings with lung cancer.

Material and methods: All women patients with simultaneous measurement of thyroid stimulating hormone (TSH) and/or total thyroxin (TT4) levels, and carcinoembryonic antigen (CEA) were retrospectively searched out. Patients who did not meet the afore mentioned criteria were not included in the present study.

Results: The laboratory profile of 115 postmenopausal women with hyperthyroidism during the period between January 2018 and December 2020 was retrospectively analyzed. Nine patients were found to have both hyperthyroidism and elevated CEA levels. Their measurements are shown in Table 1. The average age was 72 years. Of these, one patient was diagnosed with lung cancer.

\section{Discussion}

It has been proven that higher T4 levels are associated with an increased risk of any solid organ malignancy including lung cancer. ${ }^{2}$

Studies in animal models and in vitro have shown that thyroid hormones have a direct effect on cancer proliferation, cell apoptosis, cancer invasiveness and angiogenesis. Hyperthyroidism has an accelerating effect on onset and aggressiveness of cancer, whereas hypothyroidism has the opposite result. ${ }^{3}$ The thyroid hormone receptor THR $\alpha 1$ has been detected in non-small cell lung cancer (NSCLC) cells, but not in normal lung tissue. ${ }^{4}$ 
The mechanism seems to be mediated through the non-genomic pathway of activation of the plasma membrane receptor integrin $\alpha v \beta 3$, which is a membrane receptor for thyroid hormones., ${ }^{3,5}$

The integrin $\alpha v \beta 3$ is a structural protein of the plasma membrane of rapidly proliferating cells like many cancer cells and vasculature. ${ }^{1,3}$ It has been proven that integrin avb3 has a cell surface receptor for thyroid hormone that activates extracellular regulated kinase (ERK) 1/2. ${ }^{1}$ In vitro studies for lung cancer demonstrated that T4 increased tumor growth, angiogenesis, and metastasis. ${ }^{3}$ In small cell and non-small cells lung cancer models seems that both $\mathrm{T} 4$ and T3 increase abundance of the proliferating cell nuclear antigen (PCNA) and ERK1/2 activation. PCNA is a well-known marker of cell proliferation. ${ }^{1,3}$

In human non-small cell lung cancer cells (H522), physiological concentrations of $\mathrm{T} 4$ enhanced internalization and nuclear translocation of the integrin $\alpha \mathrm{v}$ monomer. This integrin inside the cell nucleus binds to promoters of central cancer-related genes, such as ER $\alpha$, cyclooxygenase-2, hypoxia-inducible factor- $1 \alpha(\mathrm{HIF} 1 \alpha)$, and thyroid hormone receptor $\beta 1 .^{6}$ The downstream signaling induced by T4 through ERK1/2 promotes phosphorylation of ERa-bearing lung cancer cells, an action that mimics the effect of estradiol. ${ }^{1}$

In vivo studies using a model of Lewis lung carcinoma (3LL) in the lung of C57/BL6 mice demonstrated that the administration of T4 significantly enhanced the growth of the malignancy. ${ }^{7}$
The distinct role of angiogenesis of T4 has also been described. The hormone, acting on $\alpha v \beta 3$ receptor, stimulates formation of new vessels via activation of mitogen-activated protein kinase (MAPK). ${ }^{3}$

\section{Conclusion}

This study does not indicate direct cause-effect correlation. International literature has demonstrated correlation of estrogen with carcinogenicity in lung cancer. The hyper secretion of thyroid hormones also has an action corresponding to estrogen. Increased vigilance for lung neoplasm in postmenopausal patients with hyperthyroidism may be an additional auxiliary tool in the assessment and early diagnosis of these patients especially in a Primary Health Care Setting.

\section{Consent}

The authors have obtained the written consent of the patient

\section{Conflict of Interest Statement}

The authors declare that they have no competing interests.

\section{Acknowledgments}

This research was supported by funding of the Department of Microbiology, General Hospital of Eastern Achaia, Kalavrita, Greece

\begin{tabular}{|c|c|c|c|}
\hline \multicolumn{3}{|c|}{ Table 1. TSH and CEA measurements of ninepostmenopausal women who were included in the present study } \\
\hline Patient & Age (years) & $\begin{array}{c}\text { TSH (normal } \\
\text { values } \\
0.4-4.0 \mu \mathrm{IU} / \mathrm{mL})\end{array}$ & $\begin{array}{c}\text { CEAnormal values: } \\
\text { Women smokers } 0.15-4.9 \mathrm{ng} / \mathrm{ml} \\
\text { Women nonsmokers } 0.15-2.5 \mathrm{ng} / \mathrm{ml}\end{array}$ \\
\hline 1 & 85 & 0.01 & 2.66 \\
\hline 2 & 83 & 0.14 & 3.87 \\
\hline 3 & 85 & 0.91 & 2.64 \\
\hline 4 & 78 & 1.21 & 5.32 \\
\hline 5 & 85 & 0.62 & 2.96 \\
\hline 6 & 56 & 0.61 & 3.56 \\
\hline 7 & 60 & 0.14 & 3.94 \\
\hline 8 & 56 & 0.39 & 3.45 \\
\hline 9 & 62 & 0.34 & 4.3 \\
\hline
\end{tabular}

\section{References}

1. Meng R, Tang H-Y, Westfall J, London D, Cao JH, et al. Crosstalk between Integrin avb3 and Estrogen Receptor-a Is Involved in Thyroid HormoneInduced Proliferation in Human Lung Carcinoma Cells. PLoS ONE. 2011; 6(11): e27547. doi:10.1371/journal.pone.0027547.

2. Khan SR, Chaker L, Ruiter R, Aerts JG, Hofman A, Dehghan A, Franco OH, Stricker BH, Peeters RP. Thyroid Function and Cancer Risk: The Rotterdam Study. J Clin Endocrinol Metab. 2016;101(12):5030-5036. doi: 10.1210/jc.2016-2104. Epub 2016 Sep 20. PMID: 27648963.

3. Krashin E, Piekiełko-Witkowska A, Ellis M, Ashur-Fabian O. Thyroid Hormones and Cancer: A Comprehensive Review of Preclinical and Clinical Studies. Front Endocrinol (Lausanne). 2019; 13:10:59. doi: 10.3389/fendo.2019.00059. PMID: 30814976; PMCID: PMC6381772.

4. Mohamed FEZA, Abdelaziz AO, Kasem AH, Ellethy T,
Gayyed MF. Thyroid hormone receptor $\alpha 1$ acts as a new squamous cell lung cancer diagnostic marker and poor prognosis predictor. Journal of Clinical Oncology 2021 39:15_suppl, e20508-e20508.

5. Davis P, Goglia F, Leonard J. Nongenomic actions of thyroid hormone. Nat Rev Endocrinol 2016:12:111-121. https://doi. org/10.1038/nrendo.2015.205.

6. Lin HY, Su YF, Hsieh MT, Lin S, Meng R, London D, et al. Nuclear monomeric integrin $\alpha \mathrm{v}$ in cancer cells is a coactivator regulated by thyroid hormone. FASEB J. 2013;27:3209-16. doi: 10.1096/fj.12-227132.

7. Kinoshita S, Sone S, Yamashita T, Tsubura E, Ogura T. Effects of experimental hyper- and hypothyroidism on natural defense activities against Lewis lung carcinoma and its spontaneous pulmonary metastases in C57BL/6 mice. Tokushima J Exp Med. 1991;38:25-35. 